UNIVERSIDADE DE BRASÍLIA (UNB)

FACULdADE DE ECONOMIA, ADMINISTRAÇÃO, CONTABILIDADE E CIÊNCIA DA INFORMAÇÃO E DOCUMENTAÇÃO (FACE)

Ana Lucia Oliveira Mota

Conteúdos aprendidos e Processos de EnsinoAprendizagem relacionados a Treinamento para Gestores de Projetos em um Órgão do Poder Judiciário

Brasília - DF 
Ana Lucia Oliveira Mota

\section{Conteúdos aprendidos e Processos de Ensino- Aprendizagem relacionados a Treinamento para Gestores de Projetos em um Órgão do Poder Judiciário}

Monografia apresentada ao Programa de Pós-Graduação em Administração (PPGA), da Universidade de Brasília (UnB), como requisito parcial à obtenção do grau de Especialista em Gestão Judiciária.

Orientadora: Profa. Dra . Catarina Cecília Odelius

Brasília - DF 


\section{AGRADECIMENTOS}

Ao meu Deus, pela vida, pelo amor, pelo cuidado, pela proteção, pelos livramentos, pela força, pela determinação, pela oportunidade de completar esse curso. Porque tudo o que sou e porque tudo o que tenho vem do Senhor!

Ao professor Marcus Vinícius Siqueira, coordenador do curso, pelo incentivo, compreensão e apoio.

À professora Catarina Cecília Odelius, orientadora da monografia, pela valorosa contribuição para que esse trabalho pudesse ter corpo, conteúdo e apresentação.

À professora Fátima Bruno-Faria, professora de metodologia científica, pelas dicas e orientações e por estar sempre disponível.

Ao meu esposo Sólon, pelo apoio e compreensão durante o período do curso e, principalmente, por ser, em todos os momentos, o meu porto seguro, minha fortaleza, meu amor.

Aos meus filhos Artur e Henrique, que com um olhar e uma demonstração de amor renovam as minhas forças para continuar enfrentando as dificuldades, encarando desafios e me alegrando com as vitórias. Vocês dois são o meu tesouro, a minha vitória, a minha vida!

Aos meus pais que sempre me incentivaram e apoiaram a estudar e a crescer. Devo muito do que sou, principalmente, a vocês!

Às minhas queridas irmãs Ângela e Teresa que são referências na minha vida, exemplos de persistência e vontade de estudar. Vocês contribuíram efetivamente para esse trabalho traduzindo o texto e me incentivando nos momentos difíceis. 
"Feliz o homem que acha sabedoria, e o homem que adquire conhecimento; porque melhor é o lucro que ela dá do que o da prata, e melhor a sua renda do que o ouro mais fino." Provérbios, 3; 13 e 14 


\section{RESUMO}

Esta monografia é um requisito parcial para a obtenção do título de Especialista em Gestão Judiciária pela Universidade de Brasília. Trata-se de estudo descritivo que teve como objetivo geral identificar conteúdos aprendidos e processos de aprendizagem ocorridos após a participação em um treinamento para gestores de projetos realizado em organização do Poder Judiciário, além da identificação de conhecimentos adquiridos no treinamento, a partir da percepção dos pesquisados; da identificação da relação dos conteúdos aprendidos e ensinados com a atuação como gestor de projetos e da identificação da disseminação de conteúdos aprendidos. Para a coleta de dados foram realizadas entrevistas individuais, semiestruturadas, em que se buscou obter a percepção dos participantes a respeito dos objetivos do trabalho. Como resultado, foi possível identificar os conteúdos aprendidos e os conteúdos ensinados após a participação no treinamento. Também foi possível identificar outros aspectos decorrentes da participação dos entrevistados no treinamento para gestores de projetos.

PALAVRAS-CHAVE: APRENDIZAGEM - TRANSFERÊNCIA DE APRENDIZAGEM - TREINAMENTO. 


\section{LISTA DE QUADROS}

- Mudança de Paradigma: Treinamento para Aprendizagem................................... 10

- Quadro Comparativo: Conteúdos Aprendidos e Conteúdos Ensinados.................. 17 


\section{SUMÁRIO}

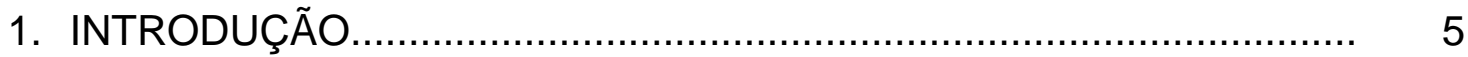

2. REVISÃO DA LITERATURA............................................................ 9

2.1. Modernização organizacional no setor público............................... 9

2.2. Treinamento e Desenvolvimento.................................................. 9

2.3. Aprendizagem e transferência de aprendizagem........................... 12

3. ASPECTOS METODOLÓGICOS DA PESQUISA.............................. 14

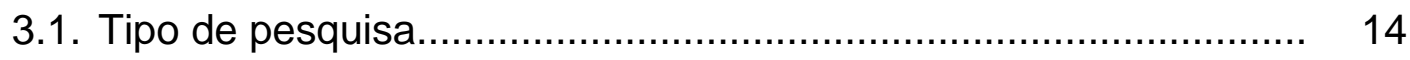

3.2. Contexto da pesquisa.............................................................. 14

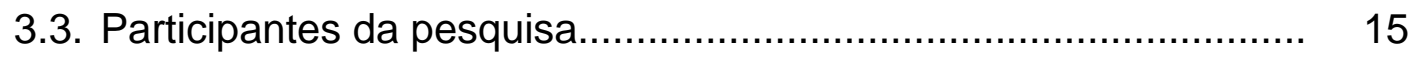

3.4. Instrumento de coleta de dados.............................................. 16

3.5. Procedimentos de coleta de dados........................................... 16

3.6. Análise dos dados................................................................. 17

4. APRESENTAÇÃO E DISCUSSÃO DOS RESULTADOS...................... 18

5. CONSIDERAÇÕES FINAIS...................................................... 19

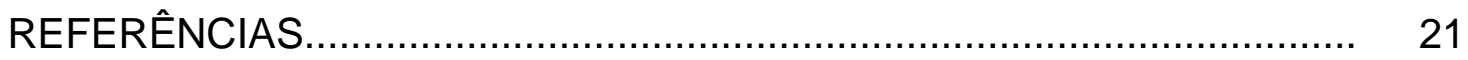

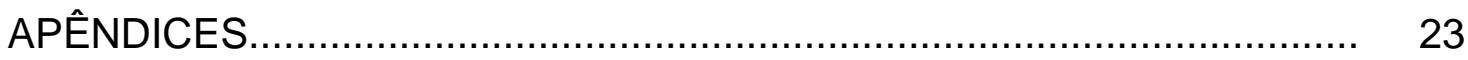

APÊNDICE A - Roteiro de Entrevista..................................................... 24 


\section{INTRODUÇÃO}

Esse trabalho faz parte das exigências para aquisição do grau de especialista no curso Gestão Judiciária, elaborado numa parceria entre Universidade de Brasília e um Tribunal, que tem como expectativa desenvolver seus servidores para que atuem como gestores públicos, e também, favorecer a produção de estudos científicos relativos à realidade e ao contexto vivenciado pelo Poder Judiciário.

O objetivo geral desse trabalho é identificar conteúdos aprendidos e processos de aprendizagem ocorridos após a participação em um treinamento para atuação como gestor de projetos realizado pela organização e com a atuação como gestor de projeto. Os objetivos específicos da pesquisa são: - identificação de conhecimentos adquiridos no curso, a partir da percepção dos pesquisados; identificação da relação dos conteúdos aprendidos e ensinados com a atuação como gestor de projetos; - identificação da disseminação de conteúdos aprendidos.

Para tanto, serão apresentados conceitos relativos a treinamento, desenvolvimento e educação em organizações, as características do curso realizado pela organização e as características dos alunos que participaram do curso. O curso foi escolhido por se tratar de um evento para capacitação de gestores de projetos, considerado estratégico para o órgão.

Kilimnik e Sant'Anna (2006) apontam que, para atender às mudanças exigidas pela sociedade atual as organizações precisam estar focadas e modificar seus processos internos de forma a atender às necessidades de seus clientes. Além disso, seus funcionários devem conhecer amplamente a organização, além de agir com autonomia, responsabilidade e ter habilidades para a tomada de decisões em ambientes cada vez mais complexos. Para os autores, "o grande desafio consiste em desenvolver pessoas com o perfil requerido por esse novo tipo de organização" (KILIMNIK; SANT'ANNA, 2006, p. 89).

É um esforço que exige transformar empregados de tarefas em profissionais de processo, repensar os papéis dos gestores e dos empregados nessa nova organização, reinventar os sistemas de gestão e fazer com que o aprendizado seja parte do dia-a-dia dos negócios da empresa, bem como moldar uma nova cultura que dê suporte à nova maneira de trabalhar (KILIMNIK; SANT'ANNA, 2006, p. 89). 
A qualificação de funcionários, portanto, tem modificado o foco das organizações, principalmente pela sua importância na implantação de novas tecnologias e técnicas de gestão. Conseqüente a todas essas transformações que as organizações têm passado, pode-se perceber mudanças no próprio trabalho, que está tornado-se mais complexo e mais incerto (BASTOS, 2006).

O ponto de partida para a realização dessa pesquisa foi um treinamento realizado pela organização estudada e que o considerou estratégico para o andamento dos projetos propostos para o biênio 2006/2008 e, conseqüentemente, para o alcance de seus objetivos para o período. O curso teve duração de 40 horas/aula e seu objetivo foi "analisar as múltiplas variáveis relacionadas à concepção de projetos estratégicos, de forma a obter subsídios para planejar, gerenciar e avaliar resultados, utilizando a metodologia do Project Management Institute - PMI, bem como uniformizar conhecimentos e capacitar os gestores dos projetos estratégicos para a elaboração e gerenciamento de projetos, conforme metodologia adotada pela 'organização'" e tinha como desempenhos esperados dos alunos ao final do curso: "delimitar o escopo do projeto; descrever os principais resultados e produtos gerados pelo projeto; fazer a análise de riscos que poderão afetar o sucesso do projeto; elencar custos; elaborar plano de comunicação do projeto, da concepção ao encerramento; definir metas e indicadores do projeto" (Processo Administrativo 3774/2006).

A metodologia do Project Management Institute - PMI - define gestão de projetos como um "conjunto de atividades de planejamento, organização e acompanhamento do trabalho visando alcançar objetivos específicos, em prazos definidos; utiliza uma perspectiva horizontal do fluxo de trabalho e geralmente forma uma estrutura matricial, em conjunto com a estrutura hierárquico-funcional da organização".

Os servidores que participaram do curso foram selecionados a partir da elaboração de um pré-projeto apresentado à Administração do Tribunal. Os préprojetos apresentados foram analisados, selecionados e apresentados à Presidência do Tribunal, que elegeu aqueles que seriam considerados estratégicos para o biênio 2006/2008. Os 35 servidores indicados como gestores dos pré-projetos eleitos estratégicos foram convidados a participar do treinamento para gestores de projetos, 30 deles aceitaram o convite ou indicaram substitutos para participar do curso. 
O problema de pesquisa a ser respondido está relacionado à identificação da ocorrência de disseminação do conteúdo aprendido em um treinamento oferecido pela organização e gerou a seguinte pergunta: Que conteúdos foram aprendidos e que processos de aprendizagem ocorreram após a participação em um treinamento para atuação como gestor de projetos?

Esta monografia está estruturada da seguinte maneira: inicialmente está apresentada a revisão de literatura, que aborda exigências oriundas da modernização das organizações, as estratégias de aprendizagem de adultos dentro de um ambiente de trabalho e, finalmente, a disseminação de conhecimentos. A metodologia utilizada para a coleta, processamento e análise de dados, a apresentações dos resultados, a discussão e as considerações finais estão apresentados na seqüência. 


\section{REVISÃO DA LITERATURA}

Nesse capítulo apresenta-se um panorama teórico a respeito das exigências oriundas da modernização das organizações, as estratégias de aprendizagem de adultos dentro de um ambiente de trabalho e, finalmente, aspectos relacionados à disseminação de conhecimentos.

\subsection{Modernização organizacional no setor público}

Tohá e Solari (1997) consideram a modernização do Estado como um processo de constituição de cidadania e de otimização de recursos públicos onde o foco está na satisfação dos usuários, na qualidade dos serviços e na promoção da consulta ao público e da transparência. Para tanto, as organizações públicas tem procurado incorporar técnicas de gestão mais modernas para adequar o seu funcionamento às expectativas de resultados dos seus usuários.

Segundo os autores, as novas políticas para modernização do Estado se apóiam em metas mensuráveis, definidas por períodos de tempo e com indicadores de sucesso divulgados e verificáveis. Esse processo de modernização é acompanhado de novos conceitos, até então ausentes, nas relações do Estado. São eles o conceito de "flexibilidade, tanto das instituições como da relação entre o Estado e seus funcionários, e o conceito de inovação permanente dos processos de tomada de decisão e nas formas de produção dos serviços públicos" (TOHÁ; SOLARI, 1997, p. 85).

Para Tohá e Solari (1997), diante desse novo contexto, a gerência pública torna-se peça fundamental nessa nova forma de entender a modernização do Estado e necessita-se mudar o papel e o perfil dos dirigentes públicos transformando-os de meros administradores dos organismos públicos para gerentes de unidades produtivas e prestadoras de serviços.

Howard (1995 apud BASTOS, 2006) descreve algumas características do novo trabalhador em grandes organizações modernas dentre as quais se destaca a necessidade de habilidades relacionais mais desenvolvidas: capacidade de comunicação, de negociação, de influência, de solucionar conflitos, entre outras. 
Essa nova característica demanda do trabalhador sensibilidade para interpretar e responder, também, às mensagens emocionais, além das cognitivas (BASTOS, 2006).

\subsection{Treinamento e Desenvolvimento}

A demanda por profissionais dotados de competências cada vez mais complexas e sofisticadas deve ser acompanhada por uma modernidade organizacional que favoreça o desenvolvimento e a aplicação das novas competências requeridas. Essa modernidade abrange a transformação do treinamento tradicional, ligado diretamente às atividades do cargo e desconectado das metas organizacionais, para um modelo voltado para o desenvolvimento mais abrangente do trabalhador.

Para Nadler (1984 apud VARGAS; ABBAD, 2006), desenvolvimento de recursos humanos refere-se às oportunidades de aprendizagem disponibilizadas para empregados, ou outros, com o objetivo de ajudar a organização a alcançar seus objetivos. Sallorenzo (2000 apud VARGAS; ABBAD, 2006) define desenvolvimento como um processo de aprendizagem mais geral, não específica para um posto de trabalho.

Já Vargas (1996) agrupa os dois conceitos - treinamento e desenvolvimento em uma única definição. Para a autora, treinamento e desenvolvimento representam a aquisição de conhecimentos de forma sistemática, os quais são capazes de gerar mudanças no agir e pensar do indivíduo, por meio da aprendizagem de novos conceitos, valores, normas e habilidades.

O interesse pelo conhecimento aprofunda-se à medida que o valor das empresas passa a ser medido pela sua capacidade de inovação, pelo talento dos seus executivos e pela competência de seus funcionários (TONET; PAZ, 2006). As autoras afirmam que o grande diferencial de uma organização é a sua capacidade de usar o conhecimento restrito a indivíduos ou a algumas áreas de tal forma que ele possa ser utilizado por outros que precisam resolver problemas similares ou em outros contextos em que aquele conhecimento se aplica. Portanto, não apenas o conhecimento torna-se um valor para as organizações, mas também o seu compartilhamento entre os funcionários. Apesar da importância do compartilhamento 
do conhecimento para as organizações, sua concretização tem-se mostrado difícil porque não há consenso empírico sobre o seu significado (TONET; PAZ, 2006).

Em grande parte das organizações, os procedimentos vigentes não permitem flexibilização das rotinas, ou adaptações a demandas específicas; muitas vezes, tais procedimentos visam exatamente a manter sem alterações a forma de execução das atividades, e preservar as situações operacionais existentes. Dificilmente as pessoas são encorajadas a reexaminar as suas rotinas de trabalho e a combater os procedimentos operacionais ineficazes. Os manuais de procedimentos, quando imutáveis, mais do que orientar a execução, funcionam como amarras que impedem as pessoas de encontrarem formas mais eficientes para realizarem o seu trabalho. (TONET; PAZ, 2006)

O Quadro 1 ilustra a mudança de paradigma do treinamento de funcionários para o foco no desenvolvimento da capacidade de aprendizado da organização, apresentado por Meister (1999, p.22). Segundo a autora, a tendência é que as organizações mudem o foco de seus esforços de treinar os funcionários de forma isolada, em sala de aula, para a criação de uma cultura de aprendizagem contínua onde a aprendizagem ocorre no dia-a-dia e uns aprendem com os outros.

Quadro 1 - Mudança de Paradigma: de Treinamento para Aprendizagem

\begin{tabular}{|c|c|c|}
\hline $\begin{array}{l}\text { Antigo paradigma de } \\
\text { treinamento }\end{array}$ & & Paradigma da Aprendizagem no século $X X I$ \\
\hline Prédio & Local & $\begin{array}{l}\text { Aprendizagem disponível sempre que } \\
\text { solicitada (em qualquer lugar, a qualquer hora) }\end{array}$ \\
\hline Atualizar qualificações técnicas & Conteúdo & $\begin{array}{l}\text { Desenvolver competências básicas do } \\
\text { ambiente de negócios }\end{array}$ \\
\hline Aprender ouvindo & Metodologia & Aprender agindo \\
\hline Funcionários internos & Público-Alvo & $\begin{array}{l}\text { Equipes de funcionários, clientes e } \\
\text { fornecedores de produtos }\end{array}$ \\
\hline $\begin{array}{l}\text { Professores, consultores de } \\
\text { universidades externas }\end{array}$ & $\begin{array}{l}\text { Corpo } \\
\text { Docente }\end{array}$ & $\begin{array}{l}\text { Gerentes seniores internos e um consórcio de } \\
\text { professores universitários e consultores }\end{array}$ \\
\hline Evento único & Freqüência & Processo contínuo de aprendizagem \\
\hline $\begin{array}{l}\text { Desenvolver o estoque de } \\
\text { qualificações do indivíduo }\end{array}$ & Meta & $\begin{array}{l}\text { Solucionar problemas empresariais reais e } \\
\text { melhorar o desempenho no trabalho }\end{array}$ \\
\hline
\end{tabular}

Fonte: MEISTER, 1999, p. 22 
A aprendizagem é definida por Abbad e Borges-Andrade (2004) como o processo em que ocorre mudança de comportamento do indivíduo. Essa mudança, afirmam os autores, é resultado da maturação do indivíduo juntamente com a sua interação com o meio. Segundo os autores, a aprendizagem ocorre nas organizações de duas formas, basicamente: a natural e a induzida:

A aprendizagem natural ocorre informalmente por tentativa e erro, imitação,
observação, busca de ajuda interpessoal, busca de materiais escritos e
contatos informais com colegas, pares, superiores, fornecedores e parceiros
de trabalho. Esse tipo de aprendizagem ocorre de modo pouco sistemático
e de acordo com as preferências, o ritmo e os estilos pessoais. A
aprendizagem induzida, por outro lado, ocorre em situações estruturadas,
criadas especialmente para otimizar os processos de aquisição, retenção e
generalização de CHAs. A essas ações chamamos genericamente de
treinamento (ABBAD; BORGES-ANDRADE, 2004, p. 270).

A transferência de aprendizagem, segundo Pilati e Abbad (2005), pode ser definida como a aplicação dos conhecimentos, habilidades e atitudes, adquiridos em treinamento, de forma eficaz no trabalho. Para Pilati e Abbad (2005), os treinamentos produzem efeitos favoráveis e permanentes e, em algumas organizações, podem fazer parte de programas de valorização ou ter como objetivo "aumentar a motivação e/ou o comprometimento organizacional, reduzir tensões e/ou conflitos internos e/ou facilitar a aceitação de mudanças organizacionais" (PILATI; ABBAD, 2005, p. 45). 


\section{ASPECTOS METODOLÓGICOS DA PESQUISA}

O presente capítulo descreve a metodologia utilizada no desenvolvimento da pesquisa realizada nesse trabalho. Serão apresentados o tipo, o contexto e os participantes da pesquisa, assim como o instrumento utilizado, os procedimentos de coleta e análise dos dados.

\subsection{Tipo de Pesquisa}

Para a definição do tipo de pesquisa a ser realizada nesse trabalho, adotou-se a taxonomia proposta por Vergara (2007) que adota dois critérios para distinguir os tipos de pesquisa e para classificá-los: quanto aos fins e quanto aos meios.

Para a autora, quanto aos fins, uma pesquisa pode ser: exploratória, descritiva, explicativa, metodológica, aplicada e intervencionista. Quanto aos meios de investigação, uma pesquisa pode ser de campo, de laboratório, documental, bibliográfica, experimental, ex post facto, participante, pesquisa ação e estudo de caso.

Para esse trabalho, a pesquisa, quanto aos fins, é descritiva, pois pretende apresentar as percepções dos pesquisados sobre a aprendizagem ocorrida, a aplicação dos conteúdos aprendidos e, também, acerca do ensino do conteúdo aprendido a outras pessoas. Quanto aos meios, é bibliográfica, pois recorreu à consulta de livros, artigos e documentos publicados que abordam o assunto e, também, de campo por pretender realizar investigação empírica com os participantes do curso.

\subsection{Contexto da pesquisa}

A pesquisa foi realizada em um órgão do Poder Judiciário, organização Pública de Direito Público, com sede em Brasília, criado pela Constituição de 1988. É composto por Ministros e tem a função de zelar pela uniformidade do direito federal e sua competência está disposta na Constituição Federal. Funciona como o 
órgão máximo da justiça comum e tem jurisdição sobre todo o território nacional e a justiça estadual e federal não especializada (BRASIL, 2005).

Foi escolhido um treinamento formal realizado pela organização com 0 objetivo de formar os gestores de projetos para atuarem em projetos estratégicos no biênio 2006/2008. O curso, portanto, foi considerado estratégico para o alcance das metas propostas para o biênio 2006/2008. O curso foi realizado em agosto de 2006, na sede do órgão, e foi desenhado para atender às necessidades específicas da organização, como horário de realização, metodologia adotada para o planejamento estratégico e para a gestão de projetos, software utilizado para acompanhamento dos projetos, exercícios práticos verdadeiros, isto é, para os exercícios práticos, cada participante descrevia e estruturava o seu próprio projeto. Os projetos já estavam em andamento e foram reestruturados a partir do curso.

O conteúdo do treinamento foi detalhado e acertado entre a instrutora, a área de gestão de pessoas e a área de planejamento estratégico. Os servidores da área de planejamento estratégico participaram tanto da escolha do instrutor e do conteúdo a ser abordado no curso como, efetivamente, do treinamento no papel de alunos e de orientadores do grupo.

\subsection{Participantes da pesquisa}

Participaram do treinamento 30 servidores da organização que, naquele período, trabalhariam com gestão de projetos. No ano de 2008 , houve mudança na presidência da organização, que foi acompanhada da saída de sete servidores que não pertenciam ao quadro de pessoal efetivo, ou seja, ocupavam apenas funções comissionadas ou cargos em comissão. Aconteceu, também, que quatro servidores efetivos da organização, que participaram do curso, foram convidados para cargos em comissão em outras organizações. Dos 19 servidores que continuaram trabalhando na organização pesquisada, perguntou-se se atuaram efetivamente como gestores de projetos e se estavam disponíveis para colaborar com a pesquisa. Oito deles responderam que não atuaram como gestores de projetos e, portanto, não aplicaram os conteúdos do curso e sete não responderam. Quatro responderam afirmativamente e compuseram o grupo entrevistado. 
Todos os entrevistados são servidores do quadro efetivo do Tribunal com mais de oito anos de trabalho na organização. Apenas um deles era gestor de área quando participou do curso e atuou como gestor de projetos, seu cargo comissionado era de coordenador de unidade. Os outros três possuíam função comissionada de assistente administrativo. Dois entrevistados são do sexo masculino e dois são do sexo feminino, todos com idade entre 39 e 49 anos. Os entrevistados têm, no mínimo, nível superior, com formações em direito, administração e psicologia.

\subsection{Instrumento de pesquisa}

A pesquisa qualitativa foi realizada por meio de entrevistas individuais semiestruturadas, e o roteiro continha perguntas formuladas com base em estudo que objetivava verificar como ocorre a aprendizagem em grupos interdisciplinares (HAYTHORNTHWAITE, 2006).

Na pesquisa foi perguntado a respeito do que foi aprendido no curso; se atuou como gestor de projetos, em qual projeto e em que período; qual foi a contribuição do curso para a atuação com gestor de projetos, e se, em sua percepção, houve disseminação desses conteúdos a outras pessoas, quer seja para os demais membros do grupo de projeto, para os colegas de trabalho, inclusive chefes e pares, ou para pessoas fora do contexto de trabalho. Para os que não atuaram como gestor de projetos, foi perguntado se aplicou os conteúdos aprendidos no curso e se sim, em que atividade ou trabalho; o que aprendeu atuando como gestor e com quem; se ensinou a outros o que aprendeu e a quem ensinou. No total, o roteiro de entrevista continha seis perguntas (Apêndice A).

\subsection{Procedimentos de coleta de dados}

As entrevistas foram realizadas no local de trabalho, em horário agendado previamente. Foi fornecida uma informação padrão inicial em todas as entrevistas em que foram apresentados os objetivos da pesquisa e as regras de sigilo e solicitou-se autorização para a gravação da entrevista (Apêndice A). 
As entrevistas tiveram duração entre nove e 29 minutos, com média de 14 minutos, totalizando 56 minutos e seis segundos de gravação.

Cada entrevista gravada foi transcrita para o papel, totalizando 14 páginas.

\subsection{Análise dos dados}

Os dados levantados nas entrevistas foram transcritos, processados e analisados utilizando-se de técnicas de análise de conteúdo. As categorias utilizadas para análise e apresentação dos dados foram: Conteúdos aprendidos, conteúdos ensinados, com quem aprendeu e para quem ensinou. 


\section{APRESENTAÇÃO E DISCUSSÃO DOS RESULTADOS}

Os dados oriundos das entrevistas serão apresentados nesse capítulo juntamente com a discussão sobre cada um deles.

Apesar da pesquisa não objetivar a análise e avaliação do treinamento realizado, o relato de todos os entrevistados retrata de forma positiva o curso como um todo, principalmente, a abordagem teórica e prática apresentada, o formato participativo, o conteúdo adaptado à realidade e à metodologia adotada pelo Tribunal, a participação ativa da equipe da área de planejamento do órgão, que transportavam a teoria apresentada para a aplicação prática que seria exigida de cada um dos gestores de projeto.

Um dos entrevistados ressalta, também, a incorporação do modelo desenvolvido à rotina de trabalho, com a utilização dos conceitos e técnicas aprendidos em outros trabalhos e na função de gerente de pessoas em suas unidades. Outro aspecto positivo apresentado foi a interação e integração com servidores de várias unidades, inclusive de servidores que atuariam como interfaces na execução dos projetos. Foi possível iniciar discussões e amadurecer idéias do projeto devido ao formato presencial do curso.

Quanto aos dados relativos aos conteúdos e processos de aprendizagem, foram categorizados de acordo com os dados registrados e foram divididos em quatro grandes categorias: Conteúdos aprendidos, conteúdos ensinados, com quem aprendeu e para quem ensinou.

Dentro da categoria conteúdos aprendidos foram identificados 12 conteúdos que os entrevistados perceberam que aprenderam. Seis desses conteúdos foram percebidos como aprendidos por dois ou mais entrevistados. Planejamento, Organização, Gestão de riscos, Comunicação, Relações, Visão do todo, Técnica de elaboração de projetos, Interfaces, Gestão de custos, Análise de problemas, Indicadores e Elaboração de Relatórios são os conteúdos aprendidos, segundo a percepção dos participantes do curso que foram entrevistados.

No conteúdo Comunicação além de constar a comunicação do projeto como uma de suas etapas, foi classificado, também, o uso da terminologia específica de projetos, fator abordado como aprendido por um dos entrevistados: "terminologia 
nova que eu não conhecia e até hoje não domino, mas aos poucos a gente foi pegando e foi entendendo melhor os conceitos".

Dos conteúdos percebidos como aprendidos, fizeram parte do conteúdo abordado no curso, segundo relato dos próprios entrevistados, as técnicas de elaboração de projetos, o planejamento do projeto, a organização do projeto, gestão de riscos, comunicação, interfaces, gestão de custos, indicadores do projeto e elaboração dos relatórios. Ressalta-se que não foram disponibilizados para a pesquisa os documentos do treinamento que descrevam o conteúdo abordado e nenhum dos entrevistados encontrou o material fornecido pelo treinamento para que fosse utilizado como comprovação do conteúdo.

$\mathrm{Na}$ categoria conteúdos ensinados, os entrevistados perceberam ensinar seis conteúdos a outras pessoas. Os conteúdos ensinados pelos entrevistados foram planejamento, organização, visão do todo, conceitos, gestão de riscos e indicadores.

Os entrevistados, portanto, perceberam aprender mais do que perceberam ensinar. Dos 12 conteúdos aprendidos, apenas seis foram ensinados a outros. Os entrevistados não se perceberam ensinando aspectos relacionados à técnica de elaboração de projetos, comunicação, interfaces, gestão de custos, elaboração de relatórios, relações e análise de problemas. Quanto aos conteúdos ensinados, um dos entrevistados percebeu ensinar conceitos a outros, um conteúdo que não havia aparecido de forma específica nos conteúdos aprendidos. O Quadro 2 ilustra a relação entre os conteúdos aprendidos e ensinados.

Quadro 2 - Quadro comparativo conteúdos aprendidos e conteúdos ensinados.

\begin{tabular}{|c|c|}
\hline Conteúdos aprendidos & Conteúdos ensinados \\
\hline Técnica de elaboração de projetos & - \\
\hline Planejamento & Planejamento \\
\hline Organização & Organização \\
\hline Gestão de riscos & Gestão de riscos \\
\hline Comunicação & - \\
\hline Interfaces & - \\
\hline Gestão de custos & - \\
\hline Indicadores & Indicadores \\
\hline Elaboração de relatórios & - \\
\hline Relações & - \\
\hline Análise de problemas & - \\
\hline Visão do todo & Visão do todo \\
\hline - & Conceitos \\
\hline
\end{tabular}

Fonte: Elaborado pela autora 
Quanto à pessoa com quem aprenderam, os dados demonstram que a aprendizagem aconteceu mediante a intervenção de três grupos: o instrutor, a equipe da área de planejamento que participou do curso e, por fim, um colega de curso e de trabalho. Todos os entrevistados ressaltaram a importância da participação da equipe da área de planejamento no curso, fazendo intervenções explicativas que influenciaram diretamente na compreensão dos participantes como também na aderência do curso à realidade do Tribunal.

Quanto a quem ensinaram, além do chefe, dos colegas de trabalho e de projeto, houve relatos de que os conceitos foram aplicados e ensinados além do ambiente de trabalho, ampliando seu alcance para a vida doméstica, na percepção dos entrevistados.

Os entrevistados perceberam que puderam aplicar os conteúdos aprendidos na atuação como gestores de projetos. Um deles, inclusive, ressalta que utiliza os conceitos aprendidos, também, na função de gerente de unidade, que ele exerce na organização. A metodologia prática adotada no curso auxiliou a vivência dos conceitos aprendidos, aumentando a percepção e a compreensão da aplicação no dia-a-dia dos entrevistados.

Um fator relevante percebido nas entrevistas é que o conteúdo aprendido no treinamento e aplicado imediatamente pelos entrevistados foi um fator importante para a concretização do aprendizado, mesmo para aquele que estava escutando os conceitos e conteúdos pela primeira vez. Os que já tinham noção dos conceitos abordados no treinamento ou que já estavam atuando como gestores de projetos antes do treinamento corroboraram essa afirmação. Para ilustrar, segue um trecho de um dos relatos:

“...nós termos trabalhado em cima de propostas efetivas, no caso as nossas, corrigindo e, quando não dizer, refazendo tudo o que a gente fez para transformar aquelas idéias iniciais que deveriam ser um projeto, realmente, agora, em um projeto (...) eu aprendi bastante..." (E3).

Esse relato além de demonstrar que a parte prática do treinamento acelerou a internalização dos conceitos aprendidos, reflete a afirmação de Bastos, Loiola e Néris (2006) descrita a seguir:

No cenário atual, em que a aquisição e manutenção de conhecimento nas organizações tornam-se cada vez mais relevantes, o treinamento tende a ser entendido sob uma perspectiva que permite ao trabalhador refletir sobre 
o que lhe é transmitido. Supõe-se, neste caso, que o treinando, ao conhecer a lógica do processo é capaz de adaptar o conteúdo aprendido a situações concretas, em vez de seguir "receitas" cegamente, o que na literatura de TD\&E é denominado de transferência de treinamento (BASTOS, LOIOLA E NÉRIS, 2006, p. 126).

A narrativa dos entrevistados versa sobre mudanças nas áreas de trabalho, como conseqüência dos conteúdos aprendidos, e podem ser identificadas nos trechos abaixo:

\begin{abstract}
"E isso repercutiu positivamente no projeto e também na minha formação como gerente repercutiu positivamente porque hoje eu emprego isso no meu dia-a-dia. Vários dos valores que eu aprendi naquele curso, como esse, e que eu julguei gerencialmente muito válidos, independentemente de projeto estratégico, eu aproveitei. E hoje e eu utilizo sempre essa visão de análise de risco, a visão de problemas e solução, sempre estou pensando na elaboração de respostas a esses riscos para minimizar seus impactos e sempre estou atrás de indicadores para as áreas" (E3).
\end{abstract}

“...teve muito impacto esse trabalho porque nós até conseguimos convencer internamente uma reestruturação da própria área para evitarmos etapas de retrabalho, para organizarmos uma área produção-atendimento, porque isso colocava em risco o dia-a-dia da atividade e isso tornou também mais célere a solução de problemas" (E3).

Foi possível observar a relação entre a aprendizagem do adulto e a sua necessidade de ação. Como o treinamento escolhido era considerado estratégico para a organização e os participantes já haviam sido nomeados gestores de projetos, criou-se a necessidade de capacitar-se para exercer o papel para o qual haviam sido nomeados. O método de utilizar os próprios projetos como base para a aprendizagem propiciou um exercício real que fixou os conceitos aprendidos, segundo a percepção dos entrevistados.

Outro fator observado na pesquisa foi a respeito da importância da capacitação dos funcionários para o avanço da organização, conforme explicitado por Schermerhorn, Hunt e Osborn (1999) e Tonet e Paz (2006), visto que os entrevistados perceberam e relataram mudanças em seus contextos de trabalho e na sua forma de agir frente ao trabalho após participarem do treinamento.

Encontram-se, também, relatos a respeito da importância das relações interpessoais e da administração de conflitos na execução dos projetos, apesar desse assunto não ter sido abordado de forma direta no treinamento, de acordo com informações dos entrevistados. O conteúdo que foi abordado no treinamento que mais se aproxima desse é sobre as interfaces do projeto e a importância de prever a negociação com esse grupo antes e durante a sua execução, segundo relato dos entrevistados. Contudo, os gestores perceberam que a administração de conflitos, a 
negociação e o cuidado com as relações interpessoais na atuação como gestor de projeto são fundamentais para o alcance dos resultados pretendidos e se configuraram como a maior dificuldade enfrentada por eles. Seguem relatos que identificam esse aspecto:

"a grande maravilha de qualquer projeto são as pessoas que atuam no projeto, por outro lado também, é a grande complicação que tem em qualquer projeto é quando tem pessoas, a questão das relações não só as interpessoais, mas as relações funcionais das pessoas dentro do projeto, as demandas que vem sobre essas pessoas que atuam no projeto, conflitando com o trabalho do projeto, a sua rotina funcional, isso eu vejo que é um grande entrave para a gestão de projetos e, na medida do possível, eu fui aprendendo como administrar esses conflitos e o meu próprio papel de gestor de projetos" (E2).

"essa questão de pessoas que não são destinadas, especificamente, para atuar no projeto, quando muito uma pessoa, o gestor do projeto, mas as demais pessoas que participam têm lá seus conflitos internos entre estar atuando no projeto e estar atuando em mil outras coisas" (E2).

"Os gestores de projetos têm muitas dificuldades no tribunal com relação à autonomia para gerenciar o seu projeto. Na maior parte das vezes, não são gerentes, hierarquicamente falando, tem que se reportar aos seus gerentes e a outros gerentes e, então, sentem que não conseguem levar o projeto adiante por conta dessa barreira hierárquica" (E1).

"Juntando-se a isso [dificuldades enfrentadas pelo gestor de projetos quanto a autonomia para gerenciar seu projeto tendo em vista que a maioria deles não era gestor hierárquico na organização] a falta de capacitação ou de habilidades para negociar com equipes, com interfaces para gerenciar custos dos projetos e a própria disposição das pessoas para gerenciar os projetos" (E1).

"[o gestor de projeto] então, não tem uma atitude pró-ativa" (E1).

“... mas era muito difícil sensibilizá-los para a importância da atuação de cada um e que era um projeto da área e não meu" (E4).

"É um problema que existe hoje aqui no trabalho, essa questão de pessoas não são destinadas especificamente para atuar no projeto, quando muito uma pessoa, o gestor do projeto, mas as demais pessoas que participam tem lá seus conflitos internos entre estar atuando no projeto e estar atuando em mil outras coisas" (E2).

A despeito das dificuldades enfrentadas pelos entrevistados, sua percepção a respeito do que foi aprendido no treinamento e na atuação como gestor de projeto é positiva, conforme relatos a seguir:

“...nesse ponto que te falei de ter uma visão do todo, do projeto, você pegar alguma coisa que seja grande, que seja mega e destrinchar isso em pedaços menores, gerenciáveis, eu acho que eu ajudei um pouquinho a chefe e colocar tudo isso numa seqüência lógica, dentro de um cronograma, eu acho que eu ajudei, dei uma contribuição" (E2). 
"...eu fui aprendendo como administrar esses conflitos e o meu próprio papel de gestor de projetos também foi um aprendizado" (E2).

"Eu não sei, a gente vai fazendo, vai executando, vai fazendo a gestão do projeto e não para muito para pensar no que foi que você aprendeu no curso e o que você já sabia ou que aprendeu depois do curso. Mas, é claro que o curso teve um papel fundamental para o início do projeto, porque eu entendo que o projeto, desde o início, ele teve uma boa estruturação, isso foi em decorrência do curso" (E2).

"Bom, e com o projeto, com o curso a gente aprendeu a fazer umas análises que a gente não sabia fazer antes como a própria análise de riscos do projeto, a análise do problema e da solução ponto a ponto e também pensar em indicadores. $E$ isso repercutiu positivamente no projeto e também na minha formação como gerente repercutiu positivamente porque hoje eu emprego isso no meu dia-a-dia" (E3).

"Antes, eu ficava apenas preocupado, como gestor, a procurar soluções e
uma alternativa, dava a alternativa, e não considerava o risco da alternativa
não ser a mais viável ou se ela fosse colocada em risco qual seria o
caminho alternativo. Sempre confiei que aquela alternativa seria a melhor,
mas nunca com uma análise de risco dela. Então, isso foi um grande
aprendizado. Durante o curso o grande mérito dele foi essa visão de gestão"
(E3).
"Outro mérito, assim, do curso foi ele organizar a seqüência de idéias,
porque, até reforçando aquilo que eu falei, até então, gerencialmente eu
tinha bem claro na minha cabeça o que tinha que ser feito, o que eu tinha
que pedir para quem para chegar aonde era o meu objetivo, mas eu nunca
tinha exercitado colocar essa seqüência de idéias e todo o seu
desmembramento numa seqüência lógica" (E3).

Dos trechos acima podemos também observar relatos que exemplificam o mecanismo de aprender fazendo, que "reflete o conhecimento disponível, aprendido pela prática" (BASTOS; LOIOLA; NÉRIS, 2006). O destaque sobre a importância de ter um bom treinamento como ponto de partida para a aprendizagem e que, no caso, possibilitou que o trabalho fosse bem estruturado e bem executado.

Em outro trecho, o indivíduo relata que a aprendizagem advinda com o treinamento ampliou sua visão da realidade e modificou, significativamente, a forma como ele analisa o contexto e toma decisões.

Adicionalmente, pode-se perceber, em outro trecho, que participar do curso permitiu que o indivíduo desenvolvesse sua capacidade de comunicação e do foco em resultado. Essa nova capacidade aprimora suas competências como gestor de projetos e como gestor de uma área.

Segundo Abbad e Borges-Andrade (2004), o conceito de transferência de aprendizagem abrange a generalização e a retenção dos conhecimentos e habilidades aprendidos e esses atributos da transferência de aprendizagem são condições indispensáveis ao uso desses conhecimentos de forma efetiva no 
trabalho. Os relatos demonstram que, apesar do treinamento ter ocorrido em agosto de 2006, em dezembro de 2008 e janeiro de 2009 os entrevistados permanecem fazendo uso dos conhecimentos e habilidades aprendidos naquela ocasião e generalizaram esses conteúdos para situações externas ao trabalho. Duas frases, nesse aspecto, merecem destaque:

\footnotetext{
"Em casa, também, eu faço uma espécie de consultoria matrimonial, a minha mulher trabalha, também com a área de gestão de pessoas, ela tem sempre projetos na área de escola e até projetos educacionais e eu via e a gente conversava sobre as dificuldades que ela tinha, e eu com a minha experiência na gestão de projetos, eu dava algumas dicas, e eu acho que consegui ajudar um pouquinho".
}

"Daí, podemos ampliar para tudo na vida, em casa, em outros trabalhos, em tudo".

Os resultados alcançados com a pesquisa, além de identificar os conteúdos aprendidos pelos entrevistados e os conteúdos ensinados por eles a outros, possibilitou identificar ocorrência de mudanças no comportamento dos indivíduos e aspectos a respeito da avaliação do treinamento, seu formato, sua metodologia e seu impacto no trabalho.

\section{CONSIDERAÇÕES FINAIS}

Os dados da pesquisa foram suficientes para identificar os conteúdos e processos de aprendizagem ocorridos em um treinamento organizado por uma organização do Poder Judiciário.

Esse trabalho pode ser considerado em decisões a respeito de treinamentos futuros na organização, principalmente nos aspectos relativos à escolha do formato do treinamento e às estratégias a serem estimuladas pela organização para a transferência de aprendizagem.

Os resultados demonstram a importância de se pensar na estrutura dos treinamentos oferecidos aos funcionários, já que um dos fatores ressaltados nas entrevistas foi a coerência do modelo apresentado no treinamento com o adotado pela organização. A metodologia prática, com a elaboração de projetos reais também foi ressaltada como um fator positivo do treinamento. Essas questões, se bem pensadas no planejamento do treinamento, podem ter papel fundamental no impacto do treinamento no trabalho. 
A pesquisa não abordou o estudo sobre a avaliação do treinamento - seu conteúdo, material didático, exercícios, formato, avaliação de aprendizagem aplicada; no resultado alcançado pelos projetos gerenciados pelos participantes do curso e qual o retorno que a organização obteve com a realização do treinamento. Esses aspectos poderão ser abordados em pesquisas futuras.

Outro aspecto que pode ser aprofundado em outras pesquisas é a respeito da metodologia de gestão de projetos adotada, se de fato melhorou a execução e o acompanhamento dos projetos e se os projetos alcançaram os resultados pretendidos.

A pesquisa é limitada na comparação entre o que foi percebido pelos entrevistados como aprendido e os conteúdos abordados, de fato, no curso. Essa limitação foi gerada pela dificuldade de acesso aos documentos e materiais relativos ao treinamento. A limitação de tempo também interferiu significativamente no seu resultado e foi devida aos prazos estabelecidos para entrega desse trabalho e a proximidade com o período de férias e recessos na organização pesquisada e na Universidade. 


\section{REFERÊNCIAS}

ABBAD, G. S.; BORGES-ANDRADE, J.E. Aprendizagem humana em organizações do trabalho. In: ZANNELI, J. C.; BORGES-ANDRADE, J.E.; BASTOS, A. V. B. (Org.). Psicologia, organizações e trabalho no Brasil. Porto Alegre: Artmed, 2004, reimpressão 2008, cap. 7.

BASTOS, A. V. B. Trabalho e qualificação: questões conceituais e desafios postos pelo cenário de reestruturação produtiva. In: BORGES-ANDRADE, J.; ABBAD, G. S.; MOURÃO, L. (Org.). Treinamento, desenvolvimento e educação em organizações do trabalho: fundamentos para a gestão de pessoas. Porto Alegre: Artmed, 2006, cap. 1.

BASTOS, A. V. B.; LOIOLA, E.; NÉRIS, J. S. Aprendizagem em organizações: mecanismos que articulam processos individuais e coletivos. In: BORGESANDRADE, J.; ABBAD, G. S.; MOURÃO, L. (Org.). Treinamento, desenvolvimento e educação em organizações do trabalho: fundamentos para a gestão de pessoas. Porto Alegre: Artmed, 2006, cap. 6

BRASIL. Constituição (1988). Lex: Texto constitucional promulgado em 5 de outubro de 1988, com as alterações adotadas pelas Emendas Constitucionais $n^{\circ}$ 1/1992 a 46/2005 e pelas Emendas Constitucionais de Revisão no 1 a 6/94, Seção III, art. 104 e art. 105. Senado Federal, Brasília, 2005.

GONDIM, S. M. G.; et al. Práticas inovadoras em gestão de produção e de pessoas e TD\&E. In: BORGES-ANDRADE, J.; ABBAD, G. S.; MOURÃO, L. (Org.). Treinamento, desenvolvimento e educação em organizações do trabalho: fundamentos para a gestão de pessoas. Porto Alegre: Artmed, 2006, cap. 3.

HAYTHORNTHWAITE, C. Learning and knowledge networks in interdisciplinary collaborations. Journal of the American Society for Information Science and Technology, v. 57, n. 8, p. 1079-1092, jun. 2006. Disponível em: Wiley InterScience www.interscience.wiley.com. Acesso em novembro de 2008.

KILIMNIK, Z. M., SANT'ANNA, A. S. Modernidade organizacional, política de gestão de pessoas e competências profissionais. In: BORGES-ANDRADE, J.; ABBAD, G. S.; MOURÃO, L. (Org.). Treinamento, desenvolvimento e educação em organizações do trabalho: fundamentos para a gestão de pessoas. Porto Alegre: Artmed, 2006, cap. 4.

MARCON, C. E. Competências gerenciais e suas contribuições no processo de aprendizagem organizacional: um estudo empírico no setor de telecomunicações brasileiro. Dissertação (Mestrado em Gestão Social e do Trabalho) - Faculdade de Economia, Administração, Contabilidade e Ciência da Informação e Documentação (FACE), Universidade de Brasília, Brasília, 2007.

MEISTER, J. C. Educação corporativa. São Paulo: Makron Books, 1999. 
PILATI, R., ABBAD, G. Análise fatorial confirmatória da escala de impacto do treinamento no trabalho. Revista Psicologia: Teoria e Pesquisa, vol. 21, n. 1, p. 4351, jan./abr. 2005.

PROJECT MANAGEMENT INSTITUTE (PMI). Um guia do conjunto de conhecimentos em gerenciamento de projetos. PMI. Newton Square, 2004.

SWIERINGA, J; WIERDSMA, A. La organización que aprende. Wilmington: AddisonWesley, 1995. In: MARCON, C. E. Competências gerenciais e suas contribuições no processo de aprendizagem organizacional: um estudo empírico no setor de telecomunicações brasileiro. Dissertação (Mestrado em Gestão Social e do Trabalho) - Faculdade de Economia, Administração, Contabilidade e Ciência da Informação e Documentação (FACE), Universidade de Brasília, Brasília, 2007, p. 32.

TOHÁ, C.; SOLARI, R. A modernização do Estado e a gerência pública. Revista do Serviço Público, ano 48, n. 3, set./dez. 1997.

TONET, H.C.; PAZ, M.G.T. Um modelo para o compartilhamento de conhecimento no trabalho. Revista de Administração Contemporânea, Curitiba, v. 10, n. 2, abr./jun, 2006.

VARGAS, M. R. M. Treinamento e desenvolvimento: reflexões sobre seus métodos. Revista de Administração, São Paulo, v. 31, n. 2, p. 126-136, abr./jun. 1996.

VARGAS, M. R. M. Educação a distância e mudança organizacional: uma análise do novo modelo de treinamento e desenvolvimento de pessoal nas organizações do século XXI. 2002. 154 f. Projeto de Qualificação (Doutorado em Psicologia) Instituto de Psicologia, Universidade de Brasília, Brasília, 2002.

VARGAS, M. R. M.; ABBAD, G. S. Bases conceituais em treinamento, desenvolvimento e educação TD\&E. In: BORGES-ANDRADE, J.; ABBAD, G. S.; MOURÃO, L. (Org.). Treinamento, desenvolvimento e educação em organizações do trabalho: fundamentos para a gestão de pessoas. Porto Alegre: Artmed, 2006, cap. 7.

VERGARA, S. C. Projetos e relatórios de pesquisa em Administração. São Paulo: Atlas, 2007. 
APÊNDICE 
UNIVERSIDADE DE BRASÍLAA(UNB)

FACULDADE DE ECONOMA, ADMINISTRAÇÃO, CONTABIIIDADEE GêNCIA DA INFORMAÇÃO E DOCUMENTAÇÃO (FACE)

PROGRAMA DE PÓS-GRADUAÇÃO EMADMINISTRAÇÃO (PPGA)

\section{APÊNDICE A}

\section{Roteiro de Entrevista}

Meu nome é Ana Lucia Oliveira Mota, sou servidora do Superior Tribunal de Justiça, Analista Judiciária, Área Administrativa e aluna do curso de Gestão Judiciária da Universidade de Brasília. Estou realizando uma pesquisa para o trabalho final do curso e essa pesquisa tem a finalidade de identificar processos e conteúdos de aprendizagem ocorridos na atuação de gestores de projetos e sua relação com o treinamento "Elaboração e Gerenciamento de Projetos", realizado em 2006. Seu nome foi escolhido como uma pessoa que poderia fornecer informações e emitir opiniões relevantes a respeito dessa atuação. Os dados coletados terão finalidade acadêmica e serão tratados de forma agregada, mantendo-se o anonimato de pessoas consultadas. Ou seja, seu nome não será mencionado nos relatórios e artigos originários da pesquisa. Esse é o meu compromisso ético: não associar percepções, julgamentos e opiniões a respeito do que the será perguntado com nomes de pessoas. Não existem respostas certas ou erradas. O que importa é a percepção de cada entrevistado a respeito do que será perguntado. Considerando a facilidade para recuperação das informações solicito sua permissão para gravar a entrevista. Isso facilitará sobremaneira a entrevista e o aproveitamento das informações dadas por você.

Por favor, descreva as características do curso "Elaboração e Gerenciamento de Projetos" que você participou em 2006.

1- O que você aprendeu nesse curso?

2- Você atuou como gestor de projetos? Se sim, Em que projetos e em qual período?

3- A - Se não atuou como gestor, você aplicou esses conteúdos aprendidos no curso? Caso positivo, especifique o quê e em que atividade/trabalho.

B - Se sim, Qual foi a contribuição do curso para a sua atuação como gestor de projetos?

4- Na atuação como gestor de projetos, relate o que você aprendeu e com quem você aprendeu.

5- Você ensinou algum desses conteúdos aprendidos no curso para outras pessoas? Caso positivo, o quê e para quem você ensinou?

6- Na atuação como gestor de projetos, relate o que você ensinou e para quem você ensinou? 